\title{
Understanding high-risk behavior among non-dominant minorities: A social resistance framework
}

\author{
Roni Factor*, Ichiro Kawachi, David R. Williams \\ Harvard School of Public Health, United States
}

\section{A R T I C L E I N F O}

Article history:

Available online 27 August 2011

\section{Keywords:}

Unhealthy behaviors

Health behaviors theory

Resistance

Acting white

Non-dominant groups

Ethnicity

Race

Socioeconomic status

Minorities

\begin{abstract}
A B S T R A C T
Across different societies, non-dominant minority groups, compared to the dominant group, often exhibit higher rates of involvement in high-risk behaviors, such as smoking, drug and alcohol use, sexual risk behaviors, overeating, and unsafe driving habits. In turn, these behaviors have a well-documented impact on chronic disease, morbidity, and mortality. Previous studies have emphasized macrostructural or micro-agentic explanations for this phenomenon. Such explanations suffer from mirrorimage shortcomings, such as, by emphasizing structural barriers, macro-level explanations leave out individual agency ("the over-socialized conception of the individual"), while micro-level theories give short shrift to structural constraints that prevent individuals from engaging in health-promoting behaviors ("the under-socialized conception of the individual"). Moreover, most current theories regard individuals as passive players who are influenced by the social environment or by psychological problems, or who make "bad" choices. The current paper develops an integrated theoretical framework that incorporates structural inequalities while leaving intact the role of individual agency. According to the social resistance framework, power relations in society encourage members of non-dominant minority groups to actively engage in everyday resistance practices that include various unhealthy behaviors. The paper develops propositions from which testable hypotheses can be generated, and discusses the implications and contributions of the social resistance framework.
\end{abstract}

(c) 2011 Elsevier Ltd. All rights reserved.

\section{Introduction}

Across different societies, a general pattern can be observed whereby members of non-dominant minority groups - mainly ethnic and/or racial minorities and individuals of low socioeconomic status - exhibit higher rates of involvement in different high-risk behaviors, compared to the country's majority or dominant group. That is, while there are differences between and within societies and some variation by age and gender, members of nondominant minority groups tend to engage at higher rates in smoking (Osypuk, Kawachi, Subramanian, \& Acevedo-Garcia, 2006; Sorensen, Barbeau, Hunt, \& Emmons, 2004), alcohol consumption, marijuana and other drug use (Friese \& Grube, 2008; Gerevich, Bacskai, Czobor, \& Szabo, 2010), as well as sexual risk and HIVrisk behaviors (Dariotis, Sifakis, Pleck, Astone, \& Sonenstein, 2011; Del Amo, 2011; Trepka et al., 2008). They tend to have poorer eating habits and to engage less in physical activity (Cockerham, 2005), and they exhibit more unsafe driving-related behaviors (failing to use seat belts, running red lights, etc.) (Braver, 2003).

\footnotetext{
* Corresponding author. Tel.: +16178173325.

E-mail address: rfactor@hsph.harvard.edu (R. Factor).
}

Given the well-established associations between high-risk behaviors and increased risk of subsequent morbidity and mortality, it is not surprising that evidence for health disparities has been found alongside behavioral disparities between nondominant minority populations and dominant majority groups in different societies (Danaei et al., 2009; Emmons, 2000). Indeed, minority-majority disparities in both high-risk behaviors and in health outcomes are remarkably common, despite differences in the genetic background of different non-dominant minority groups, and the heterogeneous historical contexts and events that led to their marginalization (e.g., through enslavement, colonization, or immigration). Thus, similar patterns can be observed in Maori New Zealanders vs. "pakeha” New Zealanders of European descent (Edwards et al., 2009); Australian Aborigines vs. white Australians (Guest, O’Dea, Carlin, \& Larkins, 1992); First Nations tribes vs. the rest of Canada (Leslie, Weiler, \& Nyomba, 2007; Oster \& Toth, 2009); aboriginal Taiwanese vs. Chinese-ethnic Taiwanese from the mainland (Ho \& Tsai, 2007; Su, Hwang, You, \& Chen, 2009); Gypsies and Travelers vs. whites in England (Peters et al., 2009); Central and Eastern European migrants vs. the general population in London (Burns et al., 2011); individuals of Turkish vs. Dutch descent in the Netherlands (Ujcic-Voortman et al., 2010); 
non-Jews vs. Jews in Israel (Factor, Mahalel, \& Yair, 2008; Factor, Yair, \& Mahalel, 2010; Nitzan Kaluski, Demem Mazengia, Shimony, Goldsmith, \& Berry, 2009); Native Americans vs. white Americans (Falk, Yi, \& Hiller-Sturmhofel, 2006; Grossman, Sugarman, Fox, \& Moran, 1997); and in African Americans (or blacks) vs. whites in the U.S. (Williams, Mohammed, Leavell, \& Collins, 2010). Similar patterns can also be observed in groups of lower socioeconomic and educational status in the U.S. (Fujiwara \& Kawachi, 2009; Phelan, Link, Diez-Roux, Kawachi, \& Levin, 2004; Sorensen et al., 2004), and where socioeconomic status intersects with race (Braveman, Cubbin, Egerter, Williams, \& Pamuk, 2010; Kawachi, Daniels, \& Robinson, 2005). In all these settings, non-dominant minority groups tend to exhibit higher rates of high-risk behaviors, and hence, excess burdens of morbidity and mortality. Barring evidence for a genetic predisposition to engage in high-risk behaviors shared by these diverse non-dominant minority groups, it is difficult - if not implausible - to attribute the observed disparities to a biological cause.

It is worth mentioning that although this pattern is widespread, there are nevertheless examples (by type of minority group and/or behavior) where non-dominant minorities do not exhibit higher rates of involvement in high-risk behaviors. For instance, in the United States, blacks and Hispanics show lower rates of current smoking than whites, and whites have the highest rate of alcohol use among all ethnic and racial groups (Centers for Disease Control and Prevention, 2005). In the Netherlands, men of Turkish origin have higher rates of smoking compared to the majority group (Dutch), but Moroccan men have lower rates than their Dutch counterparts. On the other hand, among women in the Netherlands there is no significant difference in smoking rates between people of Turkish and Dutch origin (Ujcic-Voortman et al., 2010). Moreover, there are obviously individual differences among members of any group, including minority groups. However, it is reasonable to assume that, on average, heterogeneity within groups is smaller than between groups (Burt, 2005; Factor, Mahalel, \& Yair, 2007). Therefore, notwithstanding this heterogeneity and the aforementioned exceptions to the rule, the focus of the current study is on the remarkably general pattern of minority-majority disparities.

Over the years different explanations have been put forward to explain these phenomena. In general, these can be divided into two main groups: macro-structural explanations, which focus on the structural conditions that influence individual behavioral dispositions; and micro-agentic theories, which see individual behavior as detached from structural constraints (Cockerham, 2005). Microagentic theories can be further divided into those that focus on individual factors (psychological and personality factors, on the one hand, or coping strategies on the other) and those that center on broader theories of rational choice or personal responsibility (see, e.g., Emmons, 2000; Maziak \& Ward, 2009; Sorensen et al., 2004; Williams, 1997).

These two sets of theories should not be divorced from each other. Micro-agentic theories recognize that individual behavior takes place in the context of larger societal factors, and macrostructural theories recognize that actions are performed by individuals. Yet as Cockerham (2005) pointed out, there is still no comprehensive sociological theory of health which sufficiently integrates the structure and agency explanations. Indeed, the ways in which one's place in the social structure shapes our daily life experience and affects our health are still poorly understood (Williams \& Collins, 1995). Moreover, current theories about health-related behaviors largely suffer from the same shortcoming, in that they perceive individuals as passive agents. Consequently they describe individuals as passively influenced by larger structural factors, or as making "bad" choices in light of the situation they live in.
The aim of the current paper is to develop a new approach that can serve as a bridge between structure and agency to understand unhealthy behaviors among non-dominant minority groups. According to our new framework, unhealthy behavior is not a passive product of the social structure, or a set of "bad" choices forced by circumstances. We suggest that power relations within society, and the position of non-dominant minority groups, may encourage members of these groups to actively engage, consciously or unconsciously, in different everyday resistance behaviors. These acts include unhealthy behaviors, which in turn result in higher rates of mortality and morbidity relative to the majority or dominant group.

In the sections that follow, we present our theoretical model and its theoretical and empirical foundations. We then introduce a set of propositions from which empirically testable hypotheses can be generated. We conclude with a brief discussion of the model's implications for the practice and theory of public health. For convenience, throughout the paper we use the term non-dominant minority to describe minority, ethnic, racial, and non-dominant groups, although we are aware that there are some differences among them.

\section{The social resistance framework}

According to our social resistance framework, power relations in society cause non-dominant minority groups to engage in a variety of unhealthy behaviors - such as smoking, alcohol and drug use, sexual risk behaviors, overeating, poor exercise habits, and unsafe driving behaviors - mainly through two different, but related, paths. (1) As a result of historical and/or present discrimination, members of non-dominant minority groups may feel a lack of attachment to the country and alienation from the larger society. In response, they may develop a "hidden transcript" of anonymous everyday resistance acts against the majority group (Scott, 1990). These everyday resistance acts can include behaviors that are related to negative health outcomes. By engaging in such behaviors, non-dominants express their willingness and ability to defy the country and the dominant group, as well as signaling to the dominant group that their power is not without limits. (2) Nondominant groups may also develop a collective identity in opposition to that of the dominant group. Members of the nondominant group may then feel pressure not to embrace attitudes and behaviors that are identified with the dominant group - in other words, not to be seen as "acting white" (Fordham \& Ogbu, 1986) (Although the "acting white" concept was initially introduced in the context of race relations in the U.S., we use this concept more broadly to describe relations across different races, ethnic groups, and classes in different societies.) Hence, to the extent that healthy behaviors (e.g., to practice good eating and exercise habits) are perceived by non-dominant minority groups as associated with the dominant group, members of the nondominant group may deliberately choose not to engage in those behaviors (thus, for instance, overeating and keeping a sedentary lifestyle). Both the everyday resistance path and the fear of acting white path can affect two overlapping sets of behaviors: those directly related to physical health, such as smoking, alcohol use, and weight control; and behaviors that represent commitment to the country's laws, such as compliance with road safety regulations and age-related restrictions on smoking and alcohol use.

The social resistance model, which is sketched schematically in Fig. 1, suggests a broad social-related health behavior framework for non-dominant minority groups that integrates structure and agency factors. For ease of presentation, possible feedback effects of unhealthy behavior on the antecedent variables are not shown. According to the model, institutional discrimination, everyday 


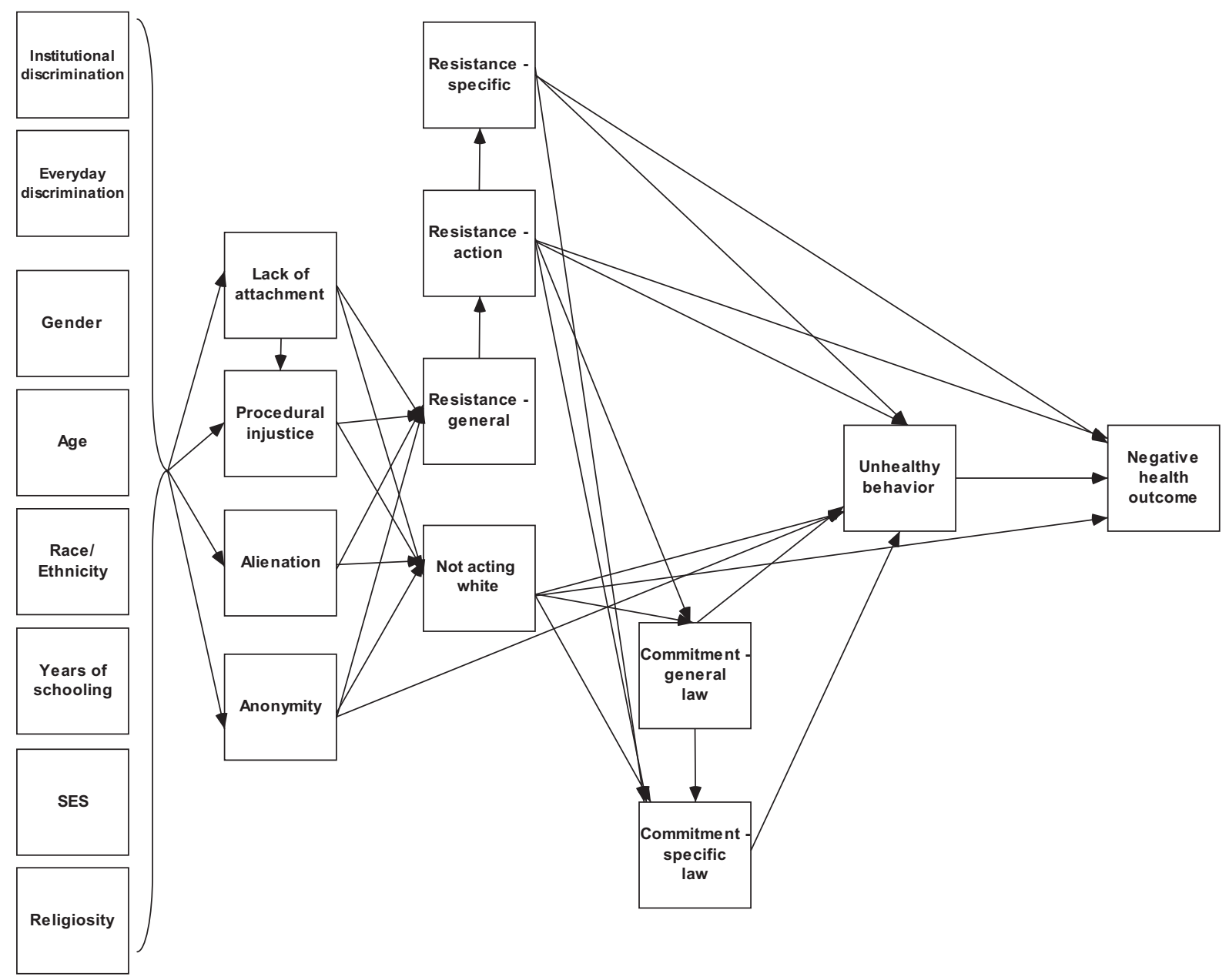

Fig. 1. Social resistance model for unhealthy behaviors among non-dominant minority groups.

discrimination, and various individual demographic and socioeconomic variables influence the lack of attachment to the country, the perception of alienation from society, perceived procedural injustice, and perceived anonymity. These factors increase the desire to avoid "acting white" and produce general resistance to the country's norms and laws. General resistance leads to a willingness to engage in different specific acts of resistance including specific unhealthy behaviors. These specific acts of resistance, along with the fear of "acting white", increase directly and indirectly - through noncompliance with specific laws and regulations - the involvement in unhealthy behaviors which eventually have negative health outcomes.

The engagement in unhealthy behaviors (particularly those that involve legal disobedience) is encouraged by the perception of nondominant group members that their behavior is taking place in an anonymous environment, i.e., in a space where the dominant group has little control. These behaviors are further reinforced by a positive feedback loop, where unhealthy behaviors provide immediate relief or gratification, whereas their negative consequences are perceived as relevant to the distant future or as having relatively low probability of being realized.

\section{Explanation of the model and hypotheses}

\section{Previous explanations of health disparities}

As noted above, different theories have been offered to explain unhealthy behaviors and elevated rates of morbidity and mortality among non-dominant minority groups. These theories can be generally divided into macro-structural and micro-agentic explanations.

Macro-structural explanations emphasize the power of structural conditions to influence the individual's attitudes and behaviors (Cockerham, 2005). Explanations in this class suggest the following factors, among others, as influencing health and health behavior disparities: residential and occupational segregation (Gee \& Payne-Sturges, 2004; Krieger, 2001; Williams, 1997, 2004); living conditions (Cockerham, 2005); utilization of, access to and quality of medical care (Friedman, Cooper, \& Osborne, 2009; Williams \& Collins, 1995); institutional discrimination, racism, discriminatory rates of arrests, and economic deprivation (Friedman et al., 2009; Williams, 2004); disparities in political and economic power (Williams \& Collins, 1995); social capital, social ties, and social cohesion (Almeida, Kawachi, Molnar, \& Subramanian, 2009; Kawachi, Subramanian, \& Kim, 2008); and culture and religious beliefs (Flynn \& Fitzgibbon, 1998; Williams, 1997).

Micro-agentic explanations focus on the individual's freelymade choices, independent of structural constraints (Cockerham, 2005). Broadly speaking, these can be further classified into four main groups, based on different sets of factors and processes. Explanations in the first two categories tend to see poor decision making as arising from psychological and personality factors, such as poor self-esteem, perceptions of control, self-regulation, or selfefficacy (Adler et al., 1994; Ajzen, 1991; Cockerham, 2005; Kwadwo, 2001; O’Haver, Melnyk, Mays, Kelly, \& Jacobson, 2009; Williams, 1997), or as coping strategies for stress, anger or hostility 
(Brosschot \& Thayer, 1998; Cozier, Wise, Palmer, \& Rosenberg, 2009; Sorensen, Barbeau, Hunt et al., 2004; Williams \& Mohammed, 2009). Explanations in the other two groups see the question in light of theories of rational choice (Baker, 2006; Maziak \& Ward, 2009) or personal responsibility (Buyx, 2008; Crawford, 1977; Minkler, 1999; Saguy \& Almeling, 2008). Indeed, we acknowledge that the classification given above is a broad generalization, and that there is variation in the way different microagentic theories acknowledge structural factors.

Neither macro-structural nor micro-agentic explanations stand on their own in explaining social and health-related disparities (see, e.g., House \& Mortimer, 1990). While agency explanations underscore the idea of individual autonomy, they recognize that this autonomy plays out in a given social context. Structural theories, meanwhile, presume some layer of human agency. A recent series of articles in a supplement of AIDS \& Behavior (Albarracin, Rothman, Di Clemente, \& del Rio, 2010) has perhaps come closest to bridging the two, presenting a framework that integrates these different levels of analysis. However, to the best of our knowledge there is no comprehensive health-related social theoretical framework that integrates structure and agency (Cockerham, 2005; Krieger, 2001). Moreover, most current theories suffer from an important shortcoming, in that they regard individuals, for the most part, as passive agents. The structural theories see individuals as reacting in various ways to the structural constraints under which they live. The agency theories see individuals as making "bad" choices (or, perhaps, failing to make good ones) because of psychological issues, or because of how circumstances have shaped their lives.

Therefore, next, we develop a health behavior framework that combines macro and micro explanations, while viewing individuals as active rather than passive agents. Our theoretical framework emphasizes the underlying motivation of members of nondominant minority groups to change the social order through social resistance, expressed, consciously or unconsciously, in different unhealthy behaviors.

\section{Non-dominant minorities and social resistance}

Turner (1986), discussing non-dominant (ethnic) minorities, describes them as members of society who are defined by others as "different" in biological, cultural, behavioral, or organizational terms. For Turner, discrimination comprises formal and informal practices which are used to deny sub-groups in society access to valued resources, so that "selected ethnics are confined to a limited range of low pay/low prestige economic positions and to ethnically homogeneous slums" (p. 410). This segregation increases interactions among members of the ethnic groups, which in turn amplifies their cultural, organizational and behavioral distinctiveness - and thus strengthens the majority's prejudices and their sense of threat from others that are different from them. The result is likely to be greater alienation of non-dominant minorities - a perception in their own minds that they are not part of society at large, as well as lower levels of attachment to the country (Huynh, Devos, \& Smalarz, 2011; Sidanius, Feshbach, Levin, \& Pratto, 1997; Tsfati, 2007; Williams, Mohammed, Leavell et al., 2010). Scott (1990) goes further, arguing that there is no dominance system which does not routinely produce insults to human dignity. Certainly, non-dominant minorities in general are weakened (in terms of their social power) by their size, status, or both (Chryssochoou \& Volpato, 2004). Hence, it is reasonable to assume that they lack the power to exert direct influence toward social change.

In recent years, the field of sociology has witnessed growing interest in the phenomenon of resistance. Hollander and Einwohner (2004) reviewed several hundred books and articles for which resistance was a central theoretical or empirical topic. Some of these studies explore different activities, such as social protest movements, violent behaviors, and resistance at workplaces, while others describe manifestations of resistance in verbal and other symbolic behaviors. According to Hollander and Einwohner, most scholars agree that resistance involves some active behavior - verbal, cognitive, or physical.

As Scott $(1985,1990)$ argued, the frustration in subordination is twofold, stemming on the one hand from a sense of humiliation and powerlessness, and on the other from the need to continually restrain the resulting anger and aggression in order to avoid more negative consequences. Powerless groups only occasionally have the opportunity to act publicly in opposition to the dominant group, and so general and broad resistance is relatively rare. "Everyday resistance," in contrast, is much easier to carry out, since "everyday acts of resistance make no headlines" (1985: xvii). Everyday resistance includes all modes in which non-dominant groups adapt to the power structure while protecting their own interests and identity (Ewick \& Silbey, 2003). It involves such tactics as humor, rumors, gestures, foot dragging, dissimulation, false compliance, pilfering, feigned ignorance, slander, arson, sabotage, and so forth (Hollander \& Einwohner, 2004; Scott, 1990) - the weapons of the weak (de Certeau, 1984; Ewick \& Silbey, 2003).

The health literature provides some indirect evidence for health-related behaviors as forms of resistance among disempowered non-dominant minority groups (though it should be clear that in most cases the authors neither define such behaviors as resistance, nor theorize the actors as active agents). For instance, Connors (1995) argued that some drug users ignore the risk of acquiring HIV/AIDS through shared needles not because they are unaware of these hazards but, rather, as a means of expressing (1) distrust of professionals and those who work for "the system"; (2) reconstitution of rules and messages; and (3) self-destruction through drug abuse. (It is worth mentioning that since the publication of Connors's paper, research has led to greater understanding of drug users' injection-related behaviors). Friedman et al. (2009) suggest that the slow response of African American organizations to HIV/AIDS can be understood in part in the context of the black community's historic struggle, which has created a mistrust of the system. Downe (1999) describes various everyday strategies of resistance used by female prostitutes in Costa Rica in order to call attention to the discriminatory and violent conditions in which they live. She clearly shows how those women use humor, jokes, and aggressive raillery as daily resistance strategies.

In this vein, it is interesting to consider the theory developed by Jackson and Knight (2006), Jackson, Knight, and Rafferty (2010) regarding the mental health paradox among African Americans namely, that African Americans suffer the same low rates of mental health problems as non-Hispanic whites, while suffering higher rates of physical health problems. The authors theorize that under stressful living conditions, individuals may engage in negative health behaviors in order to cope. However, while alleviating these stressful conditions, they expose themselves to chronic health disorders. Re-conceptualizing this provocative theory according to our resistance framework, we can see this process as an act of resistance which adds an active dimension to the African Americans' behavior, rather than seeing the behavior as simply a reaction to circumstances or a coping mechanism to relieve stress.

The distinction between resistance and coping warrants further elaboration, as there is some overlap between the two concepts. Under some circumstances, resistance may be seen as a sort of coping. However, while coping can be related to general efforts to solve interpersonal and personal problems as well as to deal with stress (see, e.g., Vierhaus, Lohaus, \& Ball, 2007), we view resistance (and everyday resistance) as an active means of expressing 
dissatisfaction with social and economic circumstances. Everyday resistance may be operationalized, for example, through items such as the following: "Often I find myself objecting to the symbols of the country"; "Sometimes I get so frustrated I feel like damaging public property"; "Sometimes my economic and social situation makes me want to show others that I am angry." On the other hand, coping has been measured, for instance, with the following items: "I take the matter into my own hands"; "I try extra hard"; "I try to calm down"; "I swear under my breath"; "I try to avoid the problem" (Vierhaus et al., 2007).

Thus, negative health behaviors may be seen as a "safety valve" (Gluckman, 1963) that reduces stress while enabling non-dominant minorities to express dissatisfaction with their status. Such everyday resistance practices may also serve to demarcate the limits of the dominant group's power - to create a boundary or imaginary line which signals to the dominant group that their control over the individual ends from this point on. In this, such behaviors may parallel deliberate self-injury or self-mutilation among prisoners, behaviors that enable the prisoner to assert his or her autonomy (see, e.g., Klonsky, 2007; Suyemoto, 1998).

The social resistance framework and everyday resistance concept thus lead to our two first hypotheses:

H1: Non-dominant minority groups that are alienated from society and have low levels of attachment to their country have higher levels of resistance to the country and the majority group.

H2: Non-dominant minority groups express their resistance to the country and the majority group through everyday resistance behaviors that include unhealthy practices.

Of course, the particular relationships between the dominant and non-dominant groups are likely to differ in different countries and societies (as a result of their particular historical context and relevant current factors). Likewise, non-dominant minority groups differ in their ability to create significant political organizations that permit active resistance through socially sanctioned means. It is reasonable to hypothesize that the magnitude of these factors could influence the relationships presented in Hypothesis 1. Therefore:

H3: Among members of non-dominant minority groups, the association between alienation from society and low levels of attachment to the country on the one hand, and higher levels of resistance on the other hand, is moderated by the level of conflict between the dominant and non-dominant groups and the non-dominant minority's ability to create significant political organizations and/ or other avenues of engagement.

In an effort to elucidate power relations between dominant and non-dominant groups, and drawing examples from the history of slavery, caste systems, colonialism, and racism, Scott (1990) developed the concept of the public versus the hidden transcript. The hidden transcript is the discourse that operates offstage, out of view of the dominant group, and it represents the fantasy of anger and aggression which is denied under conditions of domination. The hidden transcript is openly discussed only where (1) the dominant group has less ability to exert its powers of monitoring and control; and (2) where there is a relationship of trust and shared experiences among the non-dominant minority.

Clearly, fear of punishment prevents non-dominant groups from openly revealing the hidden transcript. It becomes safe to reveal the hidden transcript only when the actor can mask his or her identity. Therefore, instead of resisting openly, non-dominant groups develop an anonymous mode of attack. Anonymity is particularly important in relation to behaviors that involve legal disobedience, such as violating traffic rules or bans such as smoking in public places, underage consumption of alcohol, or use of illegal drugs.
H4: Unhealthy everyday resistance practices which involve legal disobedience will occur more frequently under circumstances that facilitate the actor's anonymity.

Resistance is heavily influenced by age. McFarland (2004) suggested that adolescents within non-dominant minority groups may adopt more rebellious attitudes, because resistance is intimately connected with the formation of identity (Field \& Olafson, 1999). Sexual risk behaviors and underage smoking and drinking, for example, can be conceptualized as acts of rebellion against the agents of the dominant system (e.g., school authorities, public health officials, law enforcement agents). Such unhealthy practices may be seen as particularly effective acts of resistance given that non-dominant minority groups tend to suffer an increased risk of disease very early in life (Williams, Mohammed, Leavell et al., 2010). Engaging in health investment behavior (e.g., abstaining from smoking or drinking) may be viewed as an act of conformity, "buying into" the dominant and paternalistic narrative which insists that a long and healthy life is achievable and desirable. Thus, beyond the power relations in society between dominant and nondominant group, we can hypothesize that:

H5: Higher levels of everyday resistance will be found among young members of non-dominant minority groups more than among adults, and more than among young members of the majority group. Young members of non-dominant minority groups consequently will engage more than adults in unhealthy everyday resistance practices.

\section{Acting white}

Fordham and Ogbu's (1986) seminal work developed the concept of "acting white" to explain African Americans' relatively poor academic achievement compared with their white peers. In a later work, Ogbu (2004) argued that neither discrimination itself - whether within society or within a particular school - nor the non-dominant minority group's reaction to this discrimination can fully explain the poor performance of minority students. He suggests that among several parts of the black community a cultural trend developed which defines academic studies and academic success as being appropriate only for the privileged class of white Americans.

According to Fordham and Ogbu (1986), different scholars have found that minority-majority conflicts produce both an oppositional social identity and an oppositional cultural frame of reference. Collective identity refers to individuals' sense of belonging to a larger whole, and is expressed through cultural symbols that reflect their attitudes, beliefs, feelings, behaviors, and languages. The group's collective identity is developed through the collective experiences present or historical - of its members, including wars, conquests, colonialism, forced labor, mass immigration, and slavery (Ogbu, 2004). Non-dominant minority groups develop a collective identity which is opposed to that of the dominant group because of the way the dominant group treats the non-dominant minority group economically, politically, socially, and psychologically - excluding them and preventing their assimilation into the larger society. Members of the non-dominant minority group perceive their treatment by the majority as an ongoing collective oppression, one that is not affected by any individual's origin, place of residence, economic status, or physical appearance (Fordham \& Ogbu, 1986). As a result, members of non-dominant minority groups react both collectively and as individuals in ways that reinforce their separate existence and collective identity (Ogbu, 2004).

In addition to an oppositional social identity, non-dominant minority groups develop an oppositional cultural frame of 
reference that provides a means by which to protect their identity and to create boundaries between themselves and the majority. Members of non-dominant minority groups perceive various behaviors, events, and symbols as being associated with the majority group (e.g., being thin, not smoking, using seat belts). Those non-dominant minority group members who behave according to the majority's frame of reference - "acting white" face hostility from their peers and risk affective dissonance (Fordham \& Ogbu, 1986).

The acting white concept is a slippery idea and politically charged. It is also the subject of ongoing debate among sociologists and anthropologists (Fryer \& Torelli, 2005). While some scholars argue that the theory makes a significant contribution to explaining low achievement among African American students and helps capture the mechanisms through which inequality is reproduced at school, other scholars have questioned its validity. Some suggest that the theory is overstated, pointing out that many other factors may influence students' performance, and that the theory does not take into account variation within the group and prior academic skills. Others argue that the concept is based on a false perception, and that African American students do not actually perceive scholastic success as representing white privilege (see, e.g., Ainsworth-Darnell \& Downey, 1998; Cook \& Ludwig, 1997; Harris, 2006; Harris \& Robinson, 2007; Horvat \& Lewis, 2003).

Nevertheless, several studies have supported the acting white and oppositional culture concepts (for instance, Austen-Smith \& Fryer, 2005; Farkas, Lleras, \& Maczuga, 2002; Fryer \& Torelli, 2005), even among other non-dominant minority groups (e.g., Italian immigrants, Indian-Americans, and Mexican-Americans) and other societies outside the United States, including Japan, New Zealand, and England (Fordham \& Ogbu, 1986; Fryer \& Torelli, 2005). In the health field, Peters, Aroian, and Flack (2006) suggested that the higher levels of hypertension seen among African Americans might be related to the acting white concept. In qualitative research, the authors suggested that African Americans' lower rates of adherence to dietary, weight, and activity recommendations may reflect their wish not to be labeled by their peers as "acting different" or "acting white". The authors note that although the acting white concept has been extensively studied in the education context, it has received little attention in the health care field. To take another example, in-depth interviews among non-Jewish drivers in Israel hint that various safe driving habits are identified with the majority (Jewish) culture, and that non-Jewish drivers who practice safety behaviors within their villages are reviled by their peers for "acting Jewish", or "acting educated" (Factor, Mahalel, \& Rafaeli, 2011). Other studies suggest that acting white can take a toll on individuals in terms of stress levels. Thompson, Lightfoot, Castillo, and Hurst (2010) found in their quantitative study among African American college students attending a predominately white university that perceptions of acting white accounted for a statistically significant proportion of the variance in acculturation stress (the stress experienced by individuals who move from their culture of origin to another culture). According to the authors, this process contributed to the students' overall stress.

In short, members of non-dominant minority groups may associate obedience to the law or making healthy lifestyle choices with the collective identity of the dominant group. To maintain their own oppositional social identity and oppositional frame of reference, members of non-dominant minority groups pressure each other not to "act white", i.e., not to embrace attitudes and behaviors that are identified with the majority group.

H6: In order to avoid "acting white" and to preserve their oppositional social identity and oppositional cultural frame of reference, members of non-dominant groups engage in various unhealthy behaviors.

Of course, not all members of all non-dominant minority groups adopt this oppositional social identity and frame of reference. As in any community, individuals adopt a wide spectrum of attitudes and behaviors (Fordham \& Ogbu, 1986). Ogbu (2004) identifies five strategies that non-dominant minorities use to cope with the burden of acting white - i.e., to address the tension between peer pressure for conformity with attitudes and behaviors that strengthen the non-dominant minority identity on the one hand, and the expectations of the larger society (e.g., for success in school) on the other hand. These strategies include: (1) cultural and linguistic assimilation; (2) accommodation without assimilation; (3) ambivalence; (4) resistance or opposition to acting white; and (5) encapsulation (i.e., not behaving like the majority group because they do not know how to, rather than because they are opposed to doing so). Therefore, the effect postulated in $\mathrm{H} 6$ will be different for different individuals, depending on the degree to which they buy into the non-dominant minority culture and reject the values of the dominant society. This effect may thus be moderated by strategies used by non-dominant minority group members to cope with the burden of acting white.

H6a: The relationship between avoiding "acting white" and various unhealthy behaviors is moderated by the degree to which individuals buy into the non-dominant minority culture and reject the values of the dominant society. Thus, along this continuum, for individuals who are more assimilated with the dominant group the "acting white" effect is weaker, whereas for those who are encapsulated in their non-dominant group the effect is stronger.

One of the recognized "dark sides" of social capital is that a very cohesive community can exert "down-leveling norms" against members of the group (Portes, 1998). Thus, excelling in the classroom is rejected as "acting white", and the group can react against individuals who strive for academic success by ostracizing them. In a similar manner, obeying the codes of healthy behavior ("don't smoke", "don't drink") may come to be viewed as conforming to the rules imposed by the dominant group. Preventing the defection of group members (e.g. by ridicule or ostracism) thereby becomes an act of collective resistance at the group level. Thus, we may hypothesize that the stronger the social capital and cohesion within a non-dominant minority group, the stronger the downleveling of norms and the greater the fear of acting white. This may partly explain the observation that social capital does not appear to have the same protective associations with health behavior in the U.S. black community as among whites (Lochner, Kawachi, Brennan, \& Buka, 2003).

H7: The stronger the social capital and cohesion within a nondominant minority group, the stronger the down-leveling health norms of group members and the fear of "acting white," and the engagement in various unhealthy behaviors

\section{Alienation, attachment to the country and legal disobedience}

Research suggests that alienation and social exclusion among non-dominant minority groups may result in a lack of commitment to the law of the land and, consequently, greater levels of noncompliance with state laws and regulations. In societies with ethnic segregation, non-dominant minority groups will have greater awareness of injustice than other groups; therefore they will tend to perceive the legal culture of the majority as less legitimate (Rattner, 1998; Rattner \& Yagil, 2004). Hagan and Albonetti (1982), for example, found that perceived injustice is more 
common among African Americans than white Americans. In a similar way, Sampson and Bartuch (1998) argue that residents of neighborhoods marked by concentrated disadvantage exhibit elevated levels of legal cynicism and dissatisfaction with the police.

Rattner, Yagil, and Pedahzur (2001) studied the attitudes of different social groups in Israel toward the judicial system and state laws. Arab respondents, a non-dominant minority group in Israel, were found to have the lowest level of support for state laws, greater readiness to take the law into their own hands, and less supportive attitudes toward the police. The authors conclude by saying: "as a minority group, they [the Arabs] are likely to feel the need to protect their group identity in various ways, among them, by 'beating the Israeli-Jewish system'” (p. 280). In a similar vein, Seeman, Seeman, and Budros (1988) found in their longitudinal study an association between alienation and alcohol use.

Therefore, we can expect that non-dominant minority groups which are alienated from society and less attached to the country will exhibit higher levels of cynicism and lack of commitment to the country's laws - including traffic laws, alcohol and drug consumption bans, and smoking restrictions - which, in turn, will result in greater levels of noncompliance and disobedience. Hence, we suggest the following hypotheses, which extend the ideas expressed in hypotheses 1 and 2 specifically to those unhealthy behaviors that are regulated by law:

H8: Among non-dominant minority groups, alienation from society and lack of attachment to the country are related to low commitment to the country's laws.

H9: Among non-dominant minority groups, low commitment to the country's laws will result in greater levels of disobedience to the law in general, and to specific health-related laws, such as traffic laws and alcohol, drug and smoking restrictions, in particular.

\section{Discussion and conclusions}

Compared to the dominant group, non-dominant minority groups often engage at higher rates in various unhealthy behaviors - such as smoking, alcohol consumption, sexual risk behaviors, overeating, and unsafe driving habits - which have a meaningful impact on their morbidity and mortality rates. Over the years various explanations have been given to this worrying phenomenon. However, there has been a lack of integrated theories that apply both macro-structural and micro-agentic explanations. Moreover, it appears that most of the proposed theoretical frameworks regard individuals as passive players who are influenced by the social environment, are affected by psychological problems, or make "bad" choices.

In the current paper we sought to develop a comprehensive health-related theoretical framework that integrates macro and micro factors. The suggested model sees members of nondominant minority groups as individuals who actively engage in unhealthy behaviors in reaction to social power relations. That is, individuals in our model perform everyday resistance practices as a means by which to raise their social standing (at least in their own eyes). From our general theoretical model we derived ten propositions from which empirically testable hypotheses can be generated.

Our innovative theoretical model and hypotheses have several important implications for the practice and theory of public health, as well as to the sociology of health. First, to the extent that resistance is one of the underlying mechanisms that produce unhealthy behaviors among non-dominant minority groups, as our model suggests, interventions that ignore this relationship may fail to work. For instance, if people from non-dominant minority groups overeat or disobey traffic laws in order to express their resistance to the dominant group, programs designed to raise awareness of weight control or road safety will not be fully effective, because lack of knowledge is not the main problem. Therefore, it is important to develop interventions that take the resistance factor into account. Further, there is a need for a clearer empirical delineation of the processes underlying the relationship between social groups and behavior, as well as the factors that may condition the strength of this association.

Second, our social resistance framework indicates that it is important to address fundamental social causes and to understand how structure operates to increase unhealthy behaviors among non-dominant minority groups (Friedman et al., 2009; Link \& Phelan, 1995; Williams \& Collins, 1995). Reducing inequality and lessening discrimination against non-dominant groups may reduce their sense of deprivation and alienation, and consequently their levels of resistance, thus eliminating one of the main motivations for their unhealthy behaviors.

Third, we can try to shift the target of the resistance, which may result in altering the attitudes and behaviors of non-dominant minority groups. A good example is the state of Florida's antismoking "truth" campaign. This campaign, targeted at youth aged 12-17 years, aimed to expose the tobacco industry's efforts to market cigarettes as glamorous and socially appealing while denying cigarettes' addictive and deadly effects (see, e.g., Hersey, Niederdeppe, Evans, Nonnemaker, Blahut, Holden et al., 2005; Niederdeppe, Farrelly, \& Haviland, 2004; Sly, Heald, \& Ray, 2001). Various studies have shown that the truth campaign was successful in changing young people's beliefs and attitudes toward cigarette companies, as well as in reducing intentions to smoke and smoking prevalence (Cowell, Farrelly, Chou, \& Vallone, 2009; Farrelly, Davis, Duke, \& Messeri, 2009).

According to Hicks (2001), one of the seven principles that underpinned the truth campaign was its anti-manipulation strategy. He points out that "tobacco was a significant, visible, and readily available way for youth to signal that they were in control...using tobacco was a tool of rebellion" (p. 4). Apparently the fact that tobacco killed made it even more appealing. However, since it was not possible to remove young people's tool of rebellion without providing alternatives, "attacking the duplicity and manipulation of the tobacco industry became 'truth's' rebellion" ( $p$. 4). Thus, interpreting the truth anti-tobacco campaign through the lens of the social resistance framework suggests that one of the strategies behind the campaign was to change the target of resistance from parents to the tobacco companies - i.e., instead of smoking as an expression of resistance against their parents, they ceased smoking as a manifestation of resistance to the tobacco companies.

Finally, and in this vein, it may be possible to channel nondominant minority groups' frustration and resistance to less risky alternatives, with the aid of attitudinal and behavioral change agents such as the mass media, educational system, and nondominant minority leadership. Rather than turning to alcohol consumption, for instance, as a means of resistance, communities can be empowered to work together so as to actively produce social change and make themselves heard by the dominant group.

Our main objective in this study was to develop, as a starting point, a framework for understanding the general pattern of majority-minority health disparities. Future studies are needed in order to refine the model and to address important examples of heterogeneity, nuance, and deviation from the general pattern. As noted earlier, there are empirical examples which deviate from the general template of majority-minority health disparities. These include, for example, cases where (1) non-dominant minority groups show better health and health-related behaviors than the majority; (2) gender differences exist in the observed patterns; (3) 
differences are found by age and across the life course; and (4) there is variation in health and health-related behaviors within the dominant group itself. Our model serves as a framework within which to explore these diverse phenomena, and also provides an opportunity to examine the extent to which the social processes which generate these heterogeneities are themselves influenced by social resistance. Moreover, the proposed social resistance model may help shed light on apparent associations between a country's inequality level and health outcomes (Wilkinson \& Pickett, 2009). One may presume that in low-inequality countries non-dominant minorities have less reason to resist the majority group, and so will engage less in unhealthy behaviors, whereas in high-inequality countries social resistance will be stronger and will result in higher rates of unhealthy behaviors.

In short, unhealthy behaviors, as a way of expressing everyday resistance among non-dominant groups, are a complex issue, and there are many interesting questions regarding the specific contexts through which they emerge, are expressed, and change over time, as well as questions about differences between minority groups. For instance, as suggested above, we do not know the different conditions which drive non-dominant groups to respond through everyday resistance, or to choose one type of unhealthy behavior and not another (or not at all). Why, for example, do Native Americans seem to express their resistance through drinking (Friese \& Grube, 2008), while African Americans seem to do so through poor exercise and eating habits (Grzywacz \& Marks, 2001)? Relatedly, are there conditions under which social resistance can cause non-dominant minorities to engage in healthy behaviors if the majority group engages in unhealthy practices? For example, African American adolescents have lower rates of smoking than their white peers. Might choosing not to smoke in this case be seen as an act of resistance? Another interesting question is whether a certain level of class consciousness is a preliminary condition for members of low socioeconomic status to express their resistance through unhealthy behavior.

Several other questions suggest themselves as fruitful topics for future theoretical and empirical research. One possible avenue of research involves the effects of holding oppositional identities and the burden of acting white on health and health behaviors, and whether these effects vary, for instance by behavior, context or socioeconomic status. Another is whether the extent to which nondominant minorities identify with or resist the cultural practices of their country of origin - which might be affected by how long ago they or their forebears arrived in their current country - influences their healthy and unhealthy behaviors. Likewise, it might be interesting to study how the social resistance framework would operate across people with multiple identities, e.g., African American gay males.

An additional area ripe for investigation involves gender differences. Although gender differences per se are beyond the scope of this article, it is possible to conceptualize gender relations as an example of dominant and non-dominant relations. In that case, our theory can be extended and used to understand gender disparities in health and in other social contexts. While prior theory and research suggests that multiple factors contribute to gender differences in health (see, e.g., Rieker, Bird, \& Lang, 2010), the extent to which there may be an interaction between social resistance and gender, as well as whether resistance contributes to the size of gender disparities in different contexts, is worth exploring.

In conclusion, over the years various studies have described health disparities between dominant and non-dominant groups, and the involvement of non-dominant groups in unhealthy behaviors. Nevertheless, "shared observations of disparities in health, however, do not necessarily translate to common understandings of cause; it is for this reason theory is key" (Krieger, 2001:
668). In this paper, we sought to develop a critical model for explaining unhealthy behaviors among non-dominant minority groups. Our theoretical social resistance model and its related hypotheses may operate in concert with other existing social and behavioral theories in public health; they are designed to extend and complement previous theories, and by no means to replace them. We hope that the social resistance framework will help to change the way practitioners and scholars think about health inequalities, and will add to the existing literature the notion of an active dimension of individual behavior. We further hope the model and the ten hypotheses presented here will stimulate other researchers to empirically explore the framework's premises in different settings and with a variety of methods - including experiment trials and longitudinal studies - and ultimately will contribute to our understanding of this phenomenon and reduce the gaps between different segments of the population.

\section{Acknowledgments}

This project was conducted with the support of the Takemi Program in International Health at the Harvard School of Public Health.

\section{References}

Adler, N. E., Boyce, T., Chesney, M. A., Cohen, S., Folkman, S., Kahn, R. L., et al. (1994). Socioeconomic status and health. The challenge of the gradient. American Psychologist, 49(1), 15-24.

Ainsworth-Darnell, J. W., \& Downey, D. B. (1998). Assessing the oppositional culture explanation for racial/ethnic differences in school performance. American Sociological Review, 63(4), 536-553.

Ajzen, I. (1991). The theory of planned behavior. Organizational Behavior and Human Decision Processes, 50(2), 179-211.

Albarracin, D., Rothman, A. J., Di Clemente, R., \& del Rio, C. (2010). Wanted: a theoretical roadmap to research and practice across individual, interpersonal, and structural levels of analysis. AIDS and Behavior, 14(Suppl. 2), 185-188.

Almeida, J., Kawachi, I., Molnar, B. E., \& Subramanian, S. V. (2009). A multilevel analysis of social ties and social cohesion among Latinos and their neighborhoods: results from Chicago. Journal of Urban Health-Bulletin of the New York Academy of Medicine, 86(5), 745-759.

Austen-Smith, D., \& Fryer, R. G. (2005). An economic analysis of "acting white". The Quarterly Journal of Economics, 120(2), 551-583.

Baker, R. M. (2006). Economic rationality and health and lifestyle choices for people with diabetes. Social Science \& Medicine, 63(9), 2341-2353.

Braveman, P. A., Cubbin, C., Egerter, S., Williams, D. R., \& Pamuk, E. (2010). Socioeconomic disparities in health in the United States: what the patterns tell us. American Journal of Public Health, 100(Suppl. 1), S186-196.

Braver, E. R. (2003). Race, Hispanic origin, and socioeconomic status in relation to motor vehicles occupant death rates and risk factors among adults. Accident Analysis and Prevention, 35(3), 295-309.

Brosschot, J. F., \& Thayer, J. F. (1998). Anger inhibition, cardiovascular recovery, and vagal function: a model of the link between hostility and cardiovascular disease. Annals of Behavioral Medicine, 20(4), 326-332.

Burns, F. M., Evans, A. R., Mercer, C. H., Parutis, V., Gerry, C. J., Mole, R. C., et al. (2011). Sexual and HIV risk behaviour in Central and Eastern European migrants in London. Sexually Transmitted Infections, 87(4), 318-324.

Burt, R. S. (2005). Brokerage and closure: An introduction to social capital. Oxford; New York: Oxford University Press.

Buyx, A. M. (2008). Personal responsibility for health as a rationing criterion: why we don't like it and why maybe we should. Journal of Medical Ethics, 34(12), $871-874$.

Centers for Disease Control and Prevention. (2005). Behavioral risk factor surveillance system survey data. Atlanta, Georgia: U.S. Department of Health and Human Services. Centers for Disease Control and Prevention.

Chryssochoou, X., \& Volpato, C. (2004). Social influence and the power of minorities: an analysis of the Communist Manifesto. Social Justice Research, 17, 357-388.

Cockerham, W. C. (2005). Health lifestyle theory and the convergence of agency and structure. Journal of Health and Social Behavior, 46(1), 51-67.

Connors, M. M. (1995). The politics of marginalization: the appropriation of aids prevention messages among injection drug users. Culture, Medicine and Psychiatry, 19(4), 425-452.

Cook, P. J., \& Ludwig, J. (1997). Weighing the "burden of 'acting white": are there race differences in attitudes toward education? Journal of Policy Analysis and Management, 16(2), 256-278. 
Cowell, A. J., Farrelly, M. C., Chou, R., \& Vallone, D. M. (2009). Assessing the impact of the national 'truth' antismoking campaign on beliefs, attitudes, and intent to smoke by race/ethnicity. Ethnicity and Health, 14(1), 75-91.

Cozier, Y. C., Wise, L. A., Palmer, J. R., \& Rosenberg, L. (2009). Perceived racism in relation to weight change in the black women's health study. Annals of Epidemiology, 19(6), 379-387.

Crawford, R. (1977). You are dangerous to your health: the ideology and politics of victim blaming. International Journal of Health Services, 7(4), 663-680.

Danaei, G., Ding, E. L., Mozaffarian, D., Taylor, B., Rehm, J., Murray, C. J., et al. (2009) The preventable causes of death in the United States: comparative risk assessment of dietary, lifestyle, and metabolic risk factors. PLoS Medicine, 6(4), e1000058.

Dariotis, J. K., Sifakis, F., Pleck, J. H., Astone, N. M., \& Sonenstein, F. L. (2011). Racial and ethnic disparities in sexual risk behaviors and STDS during young men's transition to adulthood. Perspectives on Sexual and Reproductive Health, 43(1), 51-59.

de Certeau, M. (1984). The practice of everyday life. Berkeley: University of California Press.

Del Amo, J. (2011). The sexual health of migrants from Central and Eastern European countries in London: new methods and new data. Sexually Transmitted Diseases, 87(4), 265-266.

Downe, P. J. (1999). Laughing when it hurts: humor and violence in the lives of Costa Rican prostitutes. Women's Studies International Forum, 22(1), 63-78.

Edwards, R., Gifford, H., Waa, A., Glover, M., Thomson, G., \& Wilson, N. (2009). Beneficial impacts of a national smokefree environments law on an indigenous population: a multifaceted evaluation. International Journal for Equity in Health, 8,12 .

Emmons, K. M. (2000). Health behaviors in social context. In L. F. Berkman, \& I. Kawachi (Eds.), Social epidemiology (pp. 242-266). New York: Oxford University Press.

Ewick, P., \& Silbey, S. (2003). Narrating social structure: stories of resistance to legal authority. American Journal of Sociology, 108(6), 1328-1372.

Factor, R., Mahalel, D., \& Yair, G. (2007). The social accident: a theoretical model and a research agenda for studying the influence of social and cultural characteristics on motor vehicle accidents. Accident Analysis and Prevention, 39(5), 914-921.

Factor, R., Mahalel, D., \& Yair, G. (2008). Inter-group differences in road-traffic crash involvement. Accident Analysis and Prevention, 40(6), 2000-2007.

Factor, R., Yair, G., \& Mahalel, D. (2010). Who by accident? The social morphology of car accidents. Risk Analysis, 30(9), 1411-1423.

Factor, R., Mahalel, D., \& Rafaeli, A. (2011). Road-accident involvement among the non-Jewish population in Israel: Characteristics and causes. Haifa: Transportation Research Institute, Technion-Israel Institute of Technology.

Falk, D. E., Yi, H. Y., \& Hiller-Sturmhofel, S. (2006). An epidemiologic analysis of cooccurring alcohol and tobacco use and disorders: findings from the national epidemiologic survey on alcohol and related conditions. Alcohol Research and Health, 29(3), 162-171.

Farkas, G., Lleras, C., \& Maczuga, S. (2002). Does oppositional culture exist in minority and poverty peer groups? American Sociological Review, 67(1), $148-155$.

Farrelly, M. C., Davis, K. C., Duke, J., \& Messeri, P. (2009). Sustaining 'truth': changes in youth tobacco attitudes and smoking intentions after 3 years of a national antismoking campaign. Health Education Research, 24(1), 42-48.

Field, J. C., \& Olafson, L. J. (1999). Understanding resistance in students at risk. Canadian Journal of Education, 24(1), 70-75.

Flynn, K. J., \& Fitzgibbon, M. (1998). Body images and obesity risk among black females: a review of the literature. Annals of Behavioral Medicine, 20(1), 13-24.

Fordham, S., \& Ogbu, J. U. (1986). Black students' school success: coping with the "burden of 'acting white"'. The Urban Review, 18(3), 176-206.

Friedman, S. R., Cooper, H. L. F., \& Osborne, A. H. (2009). Structural and social contexts of HIV risk among african americans. American Journal of Public Health, 99(6), 1002-1008.

Friese, B., \& Grube, J. (2008). Differences in drinking behavior and access to alcohol between Native American and white adolescents. Journal of Drug Education, 38(3), 273-284

Fryer, R. G., \& Torelli, P. (2005). An empirical analysis of 'acting white'. NBER Working Paper Series. Cambridge, MA: National Bureau of Economic Research.

Fujiwara, T., \& Kawachi, I. (2009). Is education causally related to better health? A twin fixed-effect study in the USA. International Journal of Epidemiology, 38(5), 1310-1322.

Gee, G. C., \& Payne-Sturges, D. C. (2004). Environmental health disparities: a framework integrating psychosocial and environmental concepts. Environmental Health Perspectives, 112(17), 1645-1653.

Gerevich, J., Bacskai, E., Czobor, P., \& Szabo, J. (2010). Substance use in Roma and non-Roma adolescents. Journal of Nervous and Mental Disease, 198(6), 432-436.

Gluckman, M. (1963). Order and rebellion in tribal Africa. New York: Free Press of Glencoe.

Grossman, D. C., Sugarman, J. R., Fox, C., \& Moran, J. (1997). Motor-vehicle crashinjury risk factors among American Indians. Accident Analysis and Prevention, 29(3), 313-319.

Grzywacz, J. G., \& Marks, N. F. (2001). Social inequalities and exercise during adulthood: toward an ecological perspective. Journal of Health and Social behavior, 42(2), 202-220.

Guest, C. S., O’Dea, K., Carlin, J. B., \& Larkins, R. G. (1992). Smoking in Aborigines and persons of European descent in Southeastern Australia: prevalence and associations with food habits, body fat distribution and other cardiovascular risk factors. Australian Journal of Public Health, 16(4), 397-402.

Hagan, J., \& Albonetti, C. (1982). Race, class, and the perception of criminal injustice in America. American Journal of Sociology, 88(2), 329-355.

Harris, A. L. (2006). I (don't) hate school: revisiting oppositional culture theory of blacks' resistance to schooling. Social Forces, 85(2), 797-834.

Harris, A. L., \& Robinson, K. (2007). Schooling behaviors or prior skills? A cautionary tale of omitted variable bias within oppositional culture theory. Sociology of Education, 80(2), 139-157.

Hersey, J. C., Niederdeppe, J., Evans, W. D., Nonnemaker, J., Blahut, S., Holden, D., et al. (2005). The theory of "truth": how counter industry campaigns affect smoking behavior among teens. Health Psychology, 24(1), 22-31.

Hicks, J. J. (2001). The strategy behind Florida's "truth" campaign. Tobacco Control, $10(1), 3-5$

Ho, C. S., \& Tsai, A. C. (2007). Prevalence of overweight and obesity and its associated factors in Aboriginal Taiwanese: findings from the 2001 national health interview survey in Taiwan. Asia Pacific Journal of Clinical Nutrition, 16(3), $572-579$

Hollander, J. A., \& Einwohner, R. L. (2004). Conceptualizing resistance. Sociological Forum, 19(4), 533-554.

Horvat, E. M., \& Lewis, K. S. (2003). Reassessing the "burden of 'acting white": the importance of peer groups in managing academic success. Sociology of Education, 76(4), 265-280.

House, J. S., \& Mortimer, J. (1990). Social structure and the individual: emerging themes and new directions. Social Psychology Quarterly, 53(2), 71-80.

Huynh, Q. L., Devos, T., \& Smalarz, L. (2011). Perpetual foreigner in one's own land: potential implications for identity and psychological adjustment. Journal of Social and Clinical Psychology, 30(2), 133-162.

Jackson, J. S., \& Knight, K. M. (2006). Race and self-regulatory health behaviors: the role of the stress response and the HPA axis in physical and mental health disparities. In K. W. Schaie, \& L. L. Carstensen (Eds.), Social structures, aging, and self-regulation in the elderly (pp. 189-207). New York: Springer Pub.

Jackson, J. S., Knight, K. M., \& Rafferty, J. A. (2010). Race and unhealthy behaviors: chronic stress, the HPA axis, and physical and mental health disparities over the life course. American Journal of Public Health, 100(5), 933-939.

Kawachi, I., Daniels, N., \& Robinson, D. E. (2005). Health disparities by race and class: why both matter. Health Affairs, 24(2), 343-352.

Kawachi, I., Subramanian, S. V., \& Kim, D. (2008). Social capital and health. New York; London: Springer

Klonsky, E. D. (2007). The functions of deliberate self-injury: a review of the evidence. Clinical Psychology Review, 27(2), 226-239.

Krieger, N. (2001). Theories for social epidemiology in the 21st century: an ecosocial perspective. International Journal of Epidemiology, 30(4), 668-677.

Kwadwo, B. (2001). Determinants of condom use intentions of university students in Ghana: an application of the theory of reasoned action. Social Science $E$ Medicine, 52(7), 1057-1069.

Leslie, W. D., Weiler, H. A., \& Nyomba, B. L. (2007). Ethnic differences in adiposity and body composition: the first nations bone health study. Applied Physiology, Nutrition, and Metabolism, 32(6), 1065-1072.

Link, B. G., \& Phelan, J. (1995). Social conditions as fundamental causes of disease Journal of Health and Social Behavior80-94, (Extra Issue).

Lochner, K. A., Kawachi, I., Brennan, R. T., \& Buka, S. L. (2003). Social capital and neighborhood mortality rates in Chicago. Social Science E'Medicine, 56(8), 1797-1805.

Maziak, W., \& Ward, K. D. (2009). From health as a rational choice to health as an affordable choice. American Journal of Public Health, 99(12), 2134-2139.

McFarland, D. A. (2004). Resistance as a social drama: a study of change-oriented encounters. American Journal of Sociology, 109(6), 1249-1318.

Minkler, M. (1999). Personal responsibility for health? A review of the arguments and the evidence at century's end. Health Education and Behavior, 26(1), 121-140.

Niederdeppe, J., Farrelly, M. C., \& Haviland, M. L. (2004). Confirming "truth": more evidence of a successful tobacco counter marketing campaign in Florida. American Journal of Public Health, 94(2), 255-257.

Nitzan Kaluski, D., Demem Mazengia, G., Shimony, T., Goldsmith, R., \& Berry, E. M. (2009). Prevalence and determinants of physical activity and lifestyle in relation to obesity among schoolchildren in Israel. Public Health Nutrition, 12(6), 774-782.

O’Haver, J., Melnyk, B. M., Mays, M. Z., Kelly, S., \& Jacobson, D. (2009). The relationship of perceived and actual weight in minority adolescents. Journal of Pediatric Nursing, 24(6), 474-480.

Ogbu, J. U. (2004). Collective identity and the burden of "acting white" in black history, community, and education. The Urban Review, 36(1), 1-35.

Oster, R. T., \& Toth, E. L. (2009). Differences in the prevalence of diabetes risk-factors among first nation, metis and non-aboriginal adults attending screening clinics in rural Alberta, Canada. Rural and Remote Health, 9(2), 1170.

Osypuk, T. L., Kawachi, I., Subramanian, S. V., \& Acevedo-Garcia, D. (2006). Are state patterns of smoking different for different racial/ethnic groups? An application of multilevel analysis. Public Health Reports, 121(5), 563-577.

Peters, J., Parry, G. D., Van Cleemput, P., Moore, J., Cooper, C. L., \& Walters, S. J (2009). Health and use of health services: a comparison between gypsies and travellers and other ethnic groups. Ethnicity and Health, 14(4), 359-377.

Peters, R. M., Aroian, K. J., \& Flack, J. M. (2006). African American culture and hypertension prevention. Western Journal of Nursing Research, 28(7), 831-863.

Phelan, J. C., Link, B. G., Diez-Roux, A., Kawachi, I., \& Levin, B. (2004). "Fundamenta causes" of social inequalities in mortality: a test of the theory. Journal of Health and Social Behavior, 45(3), 265-285. 
Portes, A. (1998). Social capital: its origins and applications in modern sociology. Annual Review of Sociology, 24, 1-24.

Rattner, A. (1998). Structural models of injustice and illegalism in Israel. Journal of Quantitative Criminology, 14(4), 379-396.

Rattner, A., \& Yagil, D. (2004). Taking the law into one's own hands on ideological grounds. International Journal of the Sociology of Law, 32(1), 85-102.

Rattner, A., Yagil, D., \& Pedahzur, A. (2001). Not bound by the law: legal disobedience in Israeli society. Behavioral Sciences and the Law, 19(2), 265-283.

Rieker, P. P., Bird, C. E. \& Lang, M. E. (2010). Understanding gender and health: old patterns, new trends, and future directions. In C. E. Bird, P. Conrad, \& A. M. Fremont (Eds.), Handbook of medical sociology, Nashville.

Saguy, A. C., \& Almeling, R. (2008). Fat in the fire? Science, the news media, and the "obesity epidemic". Sociological Forum, 23(1), 53-83.

Sampson, R. J., \& Bartuch, D. J. (1998). Legal cynicism and (subcultural?) tolerance of deviance: the neighborhood context of racial differences. Law and Society Review, 32(4), 777-804.

Scott, J. C. (1985). Weapons of the weak: Everyday forms of peasant resistance. New Haven: Yale University Press.

Scott, J. C. (1990). Domination and the arts of resistance: Hidden transcripts. New Haven: Yale University Press.

Seeman, M., Seeman, A. Z., \& Budros, A. (1988). Powerlessness, work, and community - a longitudinal-study of alienation and alcohol-use. Journal of Health and Social Behavior, 29(3), 185-198.

Sidanius, J., Feshbach, S., Levin, S., \& Pratto, F. (1997). The interface between ethnic and national attachment - ethnic pluralism or ethnic dominance? Public Opinion Quarterly, 61(1), 102-133.

Sly, D. F., Heald, G. R., \& Ray, S. (2001). The Florida "truth" anti-tobacco media evaluation: design, first year results, and implications for planning future state media evaluations. Tobbaco Control, 10(1), 9-15.

Sorensen, G., Barbeau, E., Hunt, M. K., \& Emmons, K. (2004). Reducing socia disparities in tobacco use: a social-contextual model for reducing tobacco use among blue-collar workers. American Journal of Public Health, 94(2), 230-239.

Su, T. C., Hwang, L. C., You, S. L., \& Chen, C. J. (2009). Ethnic variation in hypertension prevalence of women in Taiwan. Journal of Human Hypertension, 23(3), 160-167.

Suyemoto, K. L. (1998). The functions of self-mutilation. Clinical Psychology Review, 18(5), 531-554.
Thompson, K. V., Lightfoot, N. L., Castillo, L. G., \& Hurst, M. L. (2010). Influence of family perceptions of acting white on acculturative stress in African American college students. International Journal for the Advancement of Counselling, 32(2), $144-152$.

Trepka, M. J., Kim, S., Pekovic, V., Zamor, P., Velez, E., \& Gabaroni, M. V. (2008). Highrisk sexual behavior among students of a minority-serving university in a community with a high HIV/AIDS prevalence. Journal of American College Health, 57(1), 77-84.

Tsfati, Y. (2007). Hostile media perceptions, presumed media influence, and minority alienation: the case of Arabs in Israel. Journal of Communication, 57(4), $632-651$.

Turner, J. H. (1986). Toward a unified theory of ethnic antagonism: a preliminary synthesis of three macro models. Sociological Forum, 1, 403-427.

Ujcic-Voortman, J. K., Bos, G., Baan, C. A., Uitenbroek, D. G., Verhoeff, A. P., \& Seidell, J. C. (2010). Ethnic differences in total and HDL cholesterol among Turkish, Moroccan and Dutch ethnic groups living in Amsterdam, the Netherlands. BMC Public Health, 10, 740.

Vierhaus, M., Lohaus, A., \& Ball, J. (2007). Developmental changes in coping: situational and methodological influences. Anxiety Stress and Coping, 20(3), 267-282.

Wilkinson, R. G., \& Pickett, K. (2009). The spirit level: Why greater equality makes societies stronger. New York: Bloomsbury Press.

Williams, D. R., \& Collins, C. (1995). US socioeconomic and racial-differences in health - patterns and explanations. Annual Review of Sociology, 21, 349-386.

Williams, D. R. (1997). Race and health: basic questions, emerging directions. Annals of Epidemiology, 7(5), 322-333.

Williams, D. R. (2004). Racism and health. In K. E. Whitfield (Ed.), Closing the gap: Improving the health of minority elders in the new millennium (pp. 69-80). Washington, D.C.: Gerontological Society of America.

Williams, D. R. \& Mohammed, S. A. (2009). Discrimination and racial disparities in health: evidence and needed research. Journal of Behavioral Medicine, 32(1), 20-47.

Williams, D. R., Mohammed, S. A., Leavell, J., \& Collins, C. (2010). Race socioeconomic status, and health: complexities, ongoing challenges, and research opportunities. Annals of the New York Academy of Sciences, 1186, 69-101 